\title{
Symptomatic Primary Infection Due to Human Immunodeficiency Virus Type 1: Review of 31 Cases
}

\author{
Sabine Kinloch-de Loës, Philippe de Saussure, \\ Jean-Hilaire Saurat, Hans Stalder, Bernard Hirschel, \\ and Luc H. Perrin
} From the Central Laboratory of Virology. Department of Dermatology,
Policlinic of Medicine, and Division of Infectious Diseases, Department
of Medicine, University Cantonal Hospital, Geneva, Switzerland

\begin{abstract}
In this series of 31 patients with acute infection due to human immunodeficiency virus (HIV) type 1, the male-to-female ratio was 3.4:1 and the mean age was 31.3 years. Sexual transmission accounted for $83.9 \%$ of cases; $45.2 \%$ of the patients were homosexual and $38.7 \%$ were heterosexual. The mean duration of symptoms and signs was 21 days (range, 5-60 days). Fever (87.1\%) and skin rash $(67.7 \%)$ were most commonly reported. Physical examination findings were abnormal for $96 \%$ of the patients; the oral cavity $(76.7 \%)$ and the skin $(73.3 \%)$ were the most frequently involved sites. Thirteen of 25 patients with sexually acquired infection had genital or oral ulcers, whereas five intravenous drug users had none $(P=.052)$. Thrombocytopenia was the most common hematologic abnormality and was detected in 17 of 23 patients tested. P24 antigenemia, an initially negative screening test for HIV antibody, and a low $\mathrm{CD}^{+}$lymphocyte count were noted in 23 of 29,23 of 30, and 14 of 21 tested patients, respectively.
\end{abstract}

Clinical symptoms and signs of primary infection due to human immunodeficiency virus type 1 (HIV-1) were first described at the end of 1984 in regard to a nurse who was accidentally infected by a needlestick [1]. A few months later, a review of 12 cases by Cooper et al. [2] emphasized a mononucleosis-like illness with a rapid onset as the main manifestation of the acute infectious stage. Since then, a number of case reports and reports of small series have shown an ever-evolving spectrum of clinical manifestations such as mucocutaneous lesions, odynophagia, lymphadenopathy, splenomegaly, nausea, vomiting, diarrhea, arthralgia, myalgia, headache, retroorbital pain, and neurological syndromes. The latter include serious conditions such as vasculitis, aplastic anemia, esophageal candidiasis, hepatitis, spontaneous rupture of the spleen, pneumonitis with respiratory failure, renal involvement, and rhabdomyolysis [3-18].

The clinical illness is generally self-limited, although rapid progression toward AIDS has been described [19]. Some authors have suggested that long-lasting and severe symptoms might have a negative effect on long-term prognosis and that treatment should be considered even at this very early stage of infection [20-22]. Early recognition of the primary HIV infection syndrome is of obvious importance, not only in terms of medical counseling and prevention of further disease transmission by infected patients but also because early treatment may potentially improve the long-term clinical outcome $[22,23]$.

Received 14 September 1992; revised 28 December 1992

Financial support: The Swiss National Programme for AIDS Research.

Reprints or correspondence: Dr. L. H. Perrin, Central Laboratory of Virology, University Cantonal Hospital, $\mathrm{CH}-1211$ Geneva 14, Switzerland.

Clinical Infectious Diseases 1993;17:59-65

(C) 1993 by The University of Chicago. All rights reserved.

1058-4838/93/1701-0010\$02.00
The present study analyzes the epidemiological, clinical, and laboratory data from a series of cases of symptomatic primary HIV infection. Our hospital is located in an area where medical care is easily accessible and the incidence of HIV infection is high [24]. It has an active outpatient care department and an affiliation with general practitioners; such circumstances should favor frequent recognition of primary HIV infection and permit the assessment of the relative importance of symptoms and signs.

\section{Patients and Methods}

Patients. Data concerning all the patients tested for HIV antibodies from May 1988 to May 1991 in the Central Laboratory of Virology at the Geneva University Hospital were reviewed for evidence of seroconversion. This facility acts as a reference laboratory for HIV serological testing in the Geneva area. We collected data from a total of 16 cases and prospectively included data from another 17 that were diagnosed from June 1991 to April 1992. Medical files of the 35 patients were reviewed for evidence of an illness at the time of seroconversion. The following data were recorded from the files: sex, age, risk factors, clinical symptoms and signs, the need for hospital admission, duration of hospitalization, and laboratory parameters (i.e., complete blood cell count [CBC], HIV serology, and lymphocyte subset counts).

Patients were included in the study if (1) they had a clinically evident illness at the time laboratory tests revealed HIV seroconversion and (2) they had p24 antigenemia and/or the results of an HIV antibody screening assay at presentation were negative or barely positive (optical density, $<1.000$ ) but evidence of seroconversion was subsequently revealed on western blotting. Patients without p24 antigenemia were included only if the HIV antibody screening test had been negative in the recent past (within the previous 6 months). 
Table 1. Characteristics of the study population of patients presenting with symptomatic primary HIV-I infection $(n=31)$.

\begin{tabular}{lccc}
\hline Variable & \multicolumn{1}{c}{ Male } & Female & Total \\
\hline $\begin{array}{l}\text { No. (\%) of patients } \\
\text { Mean age, y (range) }\end{array}$ & $24(77.4)$ & $7(22.6)$ & $31(100)$ \\
No. (\%) of patients with risk factor & $32.3(21.0-54.7)$ & $27.8(21.8-33.3)$ & $31.3(21.0-54.7)$ \\
$\quad$ & $14(45.2)$ & 0 & $14(45.2)$ \\
$\quad$ Homosexual contacts & $7(22.6)$ & $5(16.1)$ & $12(38.7)$ \\
$\quad$ Intravenoul contacts & $3(9.7)$ & $1(3.2)$ & $4(12.9)$ \\
$\quad$ Health care workers & 0 & $1(3.2)$ & $1(3.2)$ \\
No. (\%) of patients admitted to & & & $13(41.9)$ \\
$\quad$ hospital & $10(32.3)$ & $3(9.7)$ & $10.2(3-16)$ \\
Mean length of stay, d (range) & $9.5(3-16)$ & $12.7(7-16)$ & $21(5-60)$ \\
Mean duration of illness, d (range) & $22.9(5-60)$ & $14.0(5-21)$ &
\end{tabular}

For two patients who seroconverted, HIV serologies (p24 antigen and HIV antibody screening tests) were negative at the first medical visit.

Clinical assessment. The clinical symptoms and signs recorded were those reported by the patients at their first medical consultation and those noted during subsequent visits until complete resolution of the illness. The patients enrolled were first seen at the local university hospital as outpatients in the emergency department $(n=11)$ or in the dermatology $(n=5)$ or medical $(n=5)$ outpatient clinic or were recruited via their primary care physicians $(n=10)$. A number of them were admitted to the dermatology $(n=6)$, medical $(n=6)$, or surgical $(n=1)$ wards for diagnosis and/ or treatment.

Laboratory investigations. Serologies for HIV included an antibody screening test (HIV 1/HIV2 EIA, Abbott Laboratories, North Chicago, IL), a western blot analysis (Biotech/ Dupont, Geneva), and a p24 antigen test (HIVAG-1, Abbott). Positive p24 antigen tests were all neutralized according to the manufacturer's guidelines. The CD4 and CD8 lymphocyte counts were determined with use of standard methods, i.e., with monoclonal antibodies (Ortho Diagnostic System, Raritan, NJ) and flow cytometry (Coulter EPICS IV, Instrumente Gesellschaft AG, Zurich).

Laboratory results were retained for analysis only if the tests had been performed on samples obtained within 1 week (for CBC and HIV serology) or 2 weeks (for lymphocyte subset determination) of the first consultation.

\section{Results}

Thirty-one of 35 patients for whom HIV seroconversion was proved by laboratory tests fulfilled the selected criteria for inclusion in the study; the other four did not have clinical illness at the time of seroconversion and were therefore excluded. Table 1 shows the demographic characteristics of the study group. The male-to-female ratio was $3.4: 1$, and the majority of patients were young adults. HIV infection was sexually acquired by 26 patients $(83.9 \%)$ and that of the remaining five ( $16.1 \%$ ) was due to parenteral exposure (four of the five were intravenous drug users [IVDUs] and one was a health care worker). The rate of hospital admission for diagnosis and treatment was high (42\%). For 28 patients for whom data were sufficient, the duration of clinical symptoms was as follows: $<1$ week for 3 patients (10.7\%), 1-2 weeks for 7 (25\%), 2-3 weeks for $8(28.6 \%), 3-4$ weeks for $4(14.3 \%)$, and $>4$ weeks for $6(21.4 \%)$.

Table 2 summarizes the recorded physical complaints. Fever and a skin rash were the most common symptoms. A flulike illness was noted in almost one-half of the patients. However, involvement of the tracheobronchial tree or of the abdomen was a common feature as well. Serious CNS complaints, such as meningismus $(n=2)$ and hallucinations $(n=$

Table 2. Symptoms reported at the time of the first medical visit by 31 patients with primary HIV-1 infection.

\begin{tabular}{lc}
\hline Symptom & No. (\%) of patients \\
\hline Fever & $27(87.1)$ \\
Skin rash & $21(67.7)$ \\
Sore throat & $15(48.4)$ \\
Myalgias & $13(41.9)$ \\
Headache & $12(38.7)$ \\
Diarrhea & $10(32.3)$ \\
Abdominal pain & $10(32.3)$ \\
Arthralgias & $9(29.0)$ \\
Cough & $8(25.8)$ \\
Nausea & $8(25.8)$ \\
Malaise & $8(25.8)$ \\
Lethargy & $8(25.8)$ \\
Vomiting & $7(22.6)$ \\
Weight loss & $4(12.9)$ \\
Oral ulcers & $4(12.9)$ \\
Other* & $15(48.4)$ \\
\hline
\end{tabular}

* Other symptoms included: chest pain $(n=2)$, meningismus $(n=2)$, vaginal discharge $(n=2)$, urethritis $(n=2)$, swollen glands $(n=2)$, genital ulcers $(n=2)$. yellow sputum $(n=1)$, night sweats $(n=1)$, and melena $(n=1)$. 
Table 3. Anatomic sites involved in 30 patients with abnormal physical signs.

\begin{tabular}{lc}
\hline Site affected & No. (\%) of patients \\
\hline Skin & $22(73.3)$ \\
Oral cavity & $23(76.7)$ \\
Lymph nodes & $17(56.7)$ \\
Lungs & $4(13.3)$ \\
Abdomen and gastrointestinal tract & $10(33.3)$ \\
Genitalia & $11(36.6)$ \\
Nervous system & $4(13.3)$ \\
\hline
\end{tabular}

$1)$, were noted in two patients only. Other symptoms included swollen glands $(n=2)$, chest pain $(n=2)$, vaginal discharge $(n=2)$, genital ulcers $(n=2)$, urethritis $(n=2)$, night sweats $(n=1)$, yellow sputum $(n=1)$, melena $(n=1)$, and dark urine $(n=1)$.

Results of physical examinations are shown in Table 3. Among the 31 patients who reported symptoms, 30 had physical abnormalities when they were first examined. Fever, dermatologic lesions, and lymphadenopathy were the most frequent findings. However, systemic physical examination, particularly that of the genitalia and abdomen, revealed diagnostic clues for a large proportion of patients.

In the 21 patients with pyrexia (axillary temperature, $>37.5^{\circ} \mathrm{C}$ ), the average temperature was $38.6^{\circ} \mathrm{C}$ (range, $37.5^{\circ} \mathrm{C}-39.8^{\circ} \mathrm{C}$ ); eight patients had an average temperature of $>39^{\circ} \mathrm{C}$. For the 30 patients with physical abnormalities, findings on the skin included maculopapular rash $(n=19$; $63.3 \%)$, urticaria $(n=2 ; 6.7 \%)$, perlèche $(n=2,6.7 \%)$, and ulcerous lesions of the inguinal area $(n=1 ; 3.3 \%)$. The sites of skin involvement, in order of frequency, were the trunk ( $n$ $=20 ; 66.7 \%)$, the head $(n=14 ; 46.7 \%)$, the lower limbs $(n=$ $13 ; 43.3 \%)$, and the upper limbs $(n=11 ; 36.7 \%)$.

Examination of the oral cavities of the 30 patients with physical abnormalities showed ulcerations ( $n=12 ; 40 \%)$, enanthemas $(n=12 ; 40 \%)$, and candidiasis $(n=6 ; 20 \%)$. Enanthemas or ulcers were the only oral abnormalities in six (20\%) and seven patients (23.3\%), respectively. Five patients (16.7\%) had both enanthemas and ulcers. Candidiasis (proven by the growth of Candida albicans in culture) was the only oral abnormality in four (13.3\%) of these 30 patients; the other two patients with candidiasis $(6.7 \%)$ also had enanthemas and ulcerations.

Genital ulcerations were present in seven $(23.3 \%)$ of the 30 patients with physical abnormalities. Patients with urethral $(n=2)$ and vaginal $(n=2)$ discharges were found to have gonococcal and candidal infections, respectively. Thirteen patients (43\%) presented with either oral or genital ulcerations. The pattern of association of these lesions with a skin rash is illustrated in figure 1 . It is interesting that none of the 5 patients with parenterally acquired HIV infection had oral or genital ulcerations, whereas $13(52 \%)$ of the 25 patients with sexually acquired HIV infection $\operatorname{did}(P=.052$; Fisher's exact test).

Lymphadenopathy affected 17 patients and involved, in order of frequency, the cervical ( 15 patients), axillary (9), inguinal (8), and epitrochlear (1) lymph nodes.

Two cases of pneumonitis, both involving IVDUs, were recorded. Because of poor compliance, a thorough medical workup could not be completed in these cases. Cough and fever were noted in both cases and yellow sputum was observed in one. Oral candidiasis was present in both patients. Chest roentgenographs showed consolidation of their right lobes (middle and inferior, respectively). Two other patients without pulmonary symptoms or roentgenographic abnormalities had inspiratory crackles and rhonchi, respectively. None of these four patients required intensive care.

Examination of the abdomen and gastrointestinal tract showed evidence of esophagitis in three (10\%) of the 30 patients with physical abnormalities. Endoscopy in these three cases revealed large ulcers with pseudomembrane formation that wholly or partially involved the esophagus. Candidal infection was therefore suspected, and treatment with antifungal agents (ketoconazole or fluconazole) resulted in rapid recovery. A cytological examination that confirmed the presence of candidal organisms was performed in the one case associated with prepyloric ulcerations and melena. Profound immunosuppression with a low CD4 lymphocyte count $(178 / \mu \mathrm{L}$ and $185 / \mu \mathrm{L})$ was noted in two of these three patients. Altogether, unusual clinical presentations of primary HIV infection, such as pneumonitis, esophagitis, and acute abdominal conditions, were recorded in 10 cases (33.3\%).

Meningismus was noted in two patients. Other neurologi-

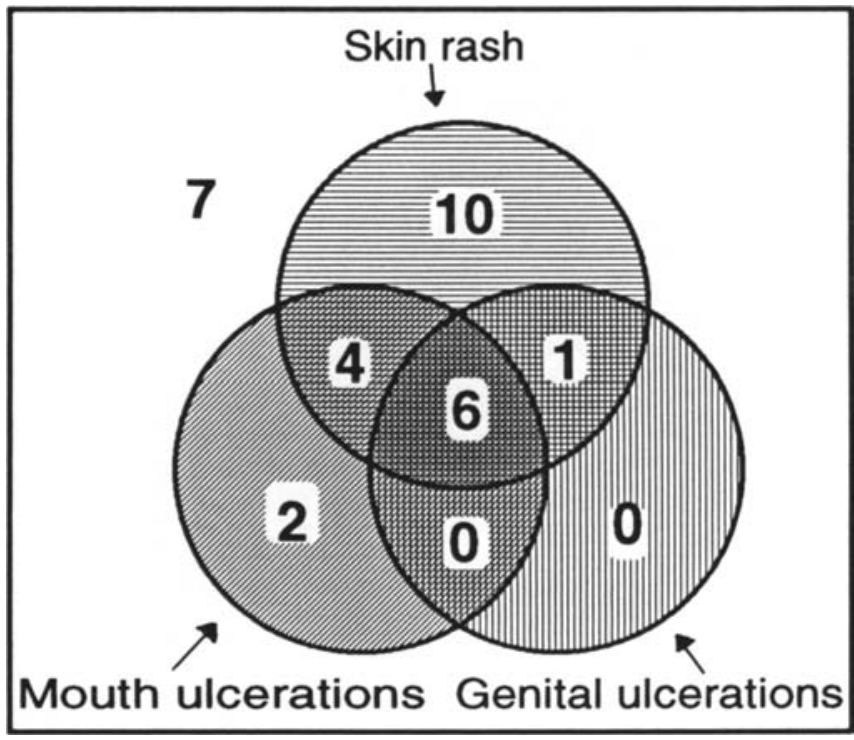

Figure 1. Pattern of association between skin rash and mouth and genital ulcerations. The numbers in the circles show how many patients had particular lesions; seven patients had none. 
Table 4. Findings related to initial complete blood cell count for 23 patients with symptomatic primary HIV-1 infection.

\begin{tabular}{lc}
\hline Finding (perinent cell count) & No. $(\%)$ of patients \\
\hline Thrombocytopenia $\left(<150 \times 10^{3} / \mu \mathrm{L}\right)$ & $17(73.9)$ \\
Leukopenia $(<4.000 / \mu \mathrm{L})$ & $11(47.8)$ \\
Neutropenia $(<1.500 / \mu \mathrm{L})$ & $8(34.8)$ \\
Lymphopenia $(<1.000 / \mu \mathrm{L})$ & $7(30.4)$ \\
Increase from normal band form count $(>500 / \mu \mathrm{L})$ & $7(30.4)$ \\
Anemia $($ Hemoglobin, $<140 \mathrm{~g} / \mathrm{L}[\mathrm{M}]$ & \\
or $<120 \mathrm{~g} / \mathrm{L}[\mathrm{F}])$ & $6(26.1)$ \\
Monocytosis $(>800 / \mu \mathrm{L})$ & $2(8.7)$ \\
Leukocytosis $(>11.000 / \mu \mathrm{L})$ & $1(4.3)$ \\
Thrombocytosis $\left(>350 \times 10^{3} / \mu \mathrm{L}\right)$ & $1(4.3)$ \\
Lymphocytosis $(>4,500 / \mu \mathrm{L})$ & 0 \\
\hline
\end{tabular}

cal abnormalities included hypoesthesia of the inner side of the thigh and slowing of mental faculties, which affected one patient each.

Table 4 shows the initial $\mathrm{CBC}$ for 23 patients for whom this value was available at the time of acute infection. The mean value of the thrombocyte count was $148,000 / \mathrm{mm}^{3}$, and thrombocytopenia ( $n=17 ; 73.9 \%$ ) was the most frequently encountered hematologic abnormality in these 23 patients.

P24 antigen was detected in the blood of $23(79.3 \%)$ of 29 patients tested at a median level of $183.5 \mathrm{ng} / \mathrm{L}$ (range, 4 $\mathrm{ng} / \mathrm{L}-47,500 \mathrm{ng} / \mathrm{L}$ ). The screening test for antibodies to HIV-1 and HIV-2 was positive (optical density, 0.2730.865 ) for seven $(23.3 \%)$ of 30 patients tested. For three patients, p24 antigenemia was associated with a positive HIV antibody screening test. For two patients, neither of these two assays was positive. Reactive bands were observed on the western blot for eight of 27 patients tested. However, the criteria for positivity of the western blot (i.e., observance of at least one reactive band in each of the gag, pol, and env domains) were fulfilled in only four cases; in all of these cases, the HIV antibody screening test was positive. Thus, western blotting did not aid in establishing an early diagnosis for the patients whose HIV antibody screening test was negative. The initial CD4 lymphocyte count was low (median, $458 / \mu \mathrm{L}$; range, $178 / \mu \mathrm{L}-1,082 / \mu \mathrm{L})$ for $14(66.7 \%)$ of 21 patients tested. The CD8 lymphocyte count was high for 9 (45\%) of 20 patients tested and low for $3(15 \%)$, with a median value of $953 / \mu \mathrm{L}$ (range, $134 / \mu \mathrm{L}-2,415 / \mu \mathrm{L}$ ).

\section{Discussion}

We report 31 successive cases of symptomatic acute HIV infection identified from May 1988 to April 1992 in Geneva. This incidence can be compared to that of HIV seropositivity in the same area [24], which has varied between 250 and 350 cases annually per 400,000 inhabitants for the period considered [24]. Thus, it appears that the great majority of cases were not diagnosed during the acute stage. Several factors could account for this: these patients may not have sought medical attention or have had any symptoms, an inaccurate diagnosis may have been made, or appropriate laboratory tests such as those for detection of p24 antigen and HIV antibody may not have been carried out. In the United States, 40,000 new cases annually are forecast for the early 1990 s, and it is assumed that the diagnosis of primary HIV infection will be missed in a high proportion of them [25].

Symptomatic primary HIV infection has been previously described in reports of isolated cases and of four series of 12-20 patients $[2-4,6]$, for whom a wide range of clinical findings were described. These studies, except for one that included six patients from other risk groups [6], focused exclusively on populations of male homosexuals.

The majority of our patients were infected through sexual intercourse, and a large proportion of them did not belong to the predominant risk groups (homosexuals and IVDUs). Heterosexuals represented a high proportion ( $72 \%$ of the female patients were infected by a male partner), a fact that is consistent with the recent epidemic-related trend in Western countries $[26,27]$. IVDUs, who account for $\sim 50 \%$ of HIVseropositive persons locally, seem underrepresented in our patient group, possibly as a result of two main factors [24]. First, these patients may not use our medical services as readily as individuals from other risk groups. Second, because of new preventive measures, a sharp decrease in the rate of seroconversions has occurred locally since 1988 in this population [28]. The absence of mucosal ulcers in this group and the performance of medical examinations that possibly were incomplete may have led to underdiagnosis as well. In comparison with previous studies $[2-4,6]$, the present study included a wider range of the different types of patients who may be encountered in clinical practice, in terms of both its size ( 31 patients) and patient population (male-to-female ratio, 3.4: 1 ; homosexual-to-heterosexual ratio, 1.2:1).

The high rate of hospital admissions $(42 \%)$ in comparison with that in another report [4] could be explained on three grounds. First, this was a hospital-based study, and the criteria for inclusion included symptomatic infection. Second, the diagnosis of acute HIV infection was initially missed for a number of patients who were later referred to our hospital. Third, clinical symptoms were often long-lasting and sometimes severe and therefore did not allow for outpatient care (the mean duration of illness was 3 weeks) $[2-4,6,7,20]$.

Most of the relevant medical complaints were similar to those reported in previous studies; they consisted mainly of fever, skin rash, sore throat, and flulike illness and could be considered unspecific [1-8]. The differential diagnosis at the time of admission included common infectious illnesses such as influenza, rubella, hepatitis, toxoplasmosis, syphilis, Epstein-Barr virus infection, and cytomegalovirus infection [22]. 
Diagnostic clues were found mainly when examining the oral cavity $(76.7 \%)$ and the skin $(73 \%)$ in febrile patients $(70 \%)$. Ulcers and enanthema were the most frequent abnormalities of the oral mucosa $[2,3,8,9,22,29,30]$. These ulcers were initially mistaken for herpes simplex lesions, although the absence of vesicles and negative viral cultures made this diagnosis unlikely [31]. They bore great clinical resemblance to those encountered in cases of recurrent aphthous stomatitis; however, in acute HIV infection, a wider distribution and association with general symptoms allowed this condition to be ruled out [32]. Oral ulcers in viral illnesses such as cytomegalovirus infection and rubella are unusual [33]. Ulcers that occur in cases of primary HIV infection can be distinguished from those caused by EpsteinBarr virus infection because the former are more widespread and may involve the oral mucosa, gingiva, tongue, and soft and hard portions of the palate $[22,34]$.

Skin involvement consisted predominantly of a maculopapular rash and disseminated urticaria $[3,8,10,35]$. No roseolalike or vesicular exanthema like that previously described $[1,2,9,36]$ was noted. Clinically, the maculopapular rash could be differentiated from that associated with pityriasis rosea because of the involvement of the face. lower part of the limbs, palms, and soles [37]. Furthermore, the presence of mucosal erosive manifestations was helpful in the differential diagnosis. Syphilis was excluded by serological testing, but in acute cases the association of macules and papules and the atypical aspect of mucosal lesions help rule out this diagnosis [38].

Genital mucosal involvement like that seen in $35.5 \%$ of our patients, particularly in the form of ulcers, should suggest a possible diagnosis of primary HIV infection after other causes of similar lesions, such as sexually transmitted diseases, have been excluded [4, 29, 38, 39]. We did not find any evidence of herpes simplex virus (type 1 or 2), Haemophilus ducreyi, or Treponema pallidum in our patients' lesions, but coinfection with Neisseria gonorrhoeae was noted in two cases $(6.5 \%)$.

As shown on figure 1, 52.4\% of the patients with skin lesions also had oral or genital ulcerations or both. Conversely, $84.6 \%$ of the patients with mucosal involvement also had skin lesions. This pattern of association between cutaneous and mucosal signs is uncommon in most of the illnesses discussed above and appears to be relatively specific to primary HIV infection. Whenever present, the triad of a maculopapular rash and oral and genital ulcers should be considered suggestive, as few other dermatologic or general illnesses present in this way. One should be aware of the frequent underreporting of oral and genital ulcerous lesions (table 2). Gaines et al. [3] observed similar mucosal involvement in seven (35\%) of 20 male homosexuals and suggested that the lesions might have appeared at the sites of viral inoculation during sexual activity. This theory is supported by the fact that when comparing the various risk groups, we found ero- sive lesions only in patients with sexually acquired HIV infection; however, this association did not reach statistical significance $(P=.052)$.

Abnormal pulmonary findings were observed on physical examination of four patients. Febrile pneumonitis in association with radiological signs of consolidation in two of these patients, who reported recent drug abuse, was considered to be of bacterial origin and was promptly treated with oral antibiotics. The other two patients did not require any treatment. Three case reports of pneumonitis in the setting of primary HIV infection have been published; all three describe various degrees of hypoxemia and no identifiable pathogen other than HIV [16, 40, 41]. Mechanical ventilation was required for two of the three patients; one of them was classified as having CD8 lymphocytic alveolitis. In previous studies, coughing appeared to be a frequent complaint; Gaines et al. [3] described it in regard to six of 20 patients, and Pedersen et al. [20], in regard to 19 of 46 patients. The incidence and pathogenesis of lung involvement and the cofactors that determine its type and extent are unknown, and only prospective studies will identify them.

Esophagitis was detected in at least three patients. It was considered to be of fungal origin and resolved rapidly following appropriate therapy. Several case reports and one series report $[30,42-49]$ have described this condition in the setting of primary HIV infection and have suggested that severe transient immunosuppression could be a determinant factor $[13,46,48]$. Some patients with ulcerative esophagitis [49] could be secondarily colonized by Candida organisms after antibiotic therapy; in addition, the direct role of HIV and of other viruses in this condition cannot be excluded [47]. In our series of patients, acute coinfection with CMV was ruled out by serological testing (data not shown).

Only two patients presented with severe CNS manifestations, which resolved spontaneously; this prevalence is in contrast with the great variety of neurological syndromes described in several reports [3, 6, 10, 50-54].

None of the laboratory results, except those for HIV serology, are specific. However, the hematologic parameters associated with the clinical symptoms and signs might point toward acute HIV infection. Twenty-one (91.3\%) of the 23 patients for whom such data were available had $\geq 1 \mathrm{CBC}$-related abnormality; although thrombocytopenia [55] was the most frequent one, anemia (a finding not previously reported [22]) occurred in up to one-quarter of the patients. Hemoglobin values, however, were never $<114 \mathrm{~g} / \mathrm{L}$. Other abnormalities, in particular the decrease from normal leukocyte and neutrophil counts and the increase from normal band form counts, may all be consistent with various viral, bacterial, or fungal infections when associated with fever. However, when cultures remain negative for such pathogens, the diagnosis of primary HIV infection should be entertained.

The most specific laboratory tool was the search for p24 antigen, which was detected in $79 \%$ of patients. Few system- 
atic laboratory data are available about the rate of detectability of antigenemia in symptomatic seroconverting patients. Pedersen et al. [20] detected p24 antigen in 22 (44\%) of 50 patients; Sinicco et al. [6] detected antigenemia in nine (75\%) of 12 symptomatic patients. Von Sydow et al. [56] detected antigenemia in all 12 patients tested during the first week following the onset of symptoms, but the rate of p24 antigen recovery decreased subsequently. In the present series, the use of screening tests for both p24 antigen and HIV antibody allowed for diagnosis of HIV infection in $92 \%$ of cases. The "window effect" [56] may explain the negative results of both tests for two patients. Therefore, in most instances, when clinical suspicion is high, both tests should be performed and repeated.

The results of analysis of the lymphocyte subsets were consistent with those in previous reports $[57,58]$. The diagnostic value of such an analysis remains low, but its use at least once during the acute stage can explain some of the unusual clinical presentations associated with severe immunosuppression, such as candidal esophagitis [42-49].

Finally, acute coinfection with other common infectious agents appears to be a rare event ( $N$. gonorrhoeae-related urethritis is the exception). We have diagnosed simultaneous hepatitis B virus infection in only one of 30 patients who repeatedly underwent serological testing for acute hepatitis A, B, C, and D and acute cytomegalovirus infections (data not shown). This is consistent with previous findings [4, 20].

In conclusion, primary HIV infection can be a debilitating disease that may require hospitalization for diagnosis and treatment. As the infection spreads into the heterosexual population of Western countries, its diagnosis may be missed without a high degree of clinical suspicion. Dermatologic signs that include involvement of both skin and mucosae in febrile patients should prompt rapid testing for p24 antigen and HIV antibodies for the purpose of confirming clinical suspicions.

\section{Acknowledgments}

The authors are indebted to all the physicians who referred patients to the study, to Dr. Alison Heald for reviewing the manuscript, to Mr. Patrick Schreiber for technical assistance, and to Mrs. Christine Brown for preparation of the manuscript.

\section{References}

1. Anonymous. Needlestick transmission of HTLV-III from a patient infected in Africa [editorial]. Lancet 1984;2:1376-7.

2. Cooper DA, Gold J. MacLean P. et al. Acute AIDS retrovirus infection: definition of a clinical illness associated with seroconversion. Lancet 1985; 1:537-40.

3. Gaines H, von Sydow M. Pehrson PO. Lundbergh P. Clinical picture of primary HIV infection presenting as a glandular-fever-like illness. BMJ 1988:297:1363-8.

4. Tindall B, Barker S. Donovan B, et al. Characterization of the acu: clinical illness associated with human immunodeficiency virus infection. Arch Intern Med 1988; 148:945-9.

5. Boyko WJ, Schechter MT, Craib KJP, et al. The Vancouver lymphadenopathy-AIDS study: 7. Clinical and laboratory features of 87 cases of primary HIV infection. Can Med Assoc J 1987:137:109-13.

6. Sinicco A. Palestro G. Caramello P. et al. Acute HIV-1 infection: clinical and biological study of 12 patients. J Acquir Immune Defic Syndr 1990;3:260-5.

7. Fox R, Eldred LJ. Fuchs EJ, et al. Clinical manifestations of acute infection with human immunodeficiency virus in a cohort of gay men. AIDS 1987;1:35-8.

8. Kessler HA, Blaauw B, Spear J, Paul DA, Falk LA, Landay A. Diagnosis of human immunodeficiency virus infection in seronegative homosexuals presenting with an acute viral syndrome. JAMA 1987;258:1 196-9.

9. Lindskov R, Orskov Lindhardt B, Weismann K, et al. Acute HTLV-III infection with roseola-like rash [letter]. Lancet 1986;1:447.

10. Ho DD, Sarngadharan MG, Resnick L, Dimarzo-Veronese F, Rota TR, Hirsch MS. Primary human T-lymphotropic virus type III infection. Ann Intern Med 1985;103:880-3.

11. Bernard E, Dellamonica P, Michiels JF, et al. Heparine-like anticoagulant vasculitis associated with severe primary infection by HIV. AIDS 1990;4:932-3.

12. Samuel D, Castaing D, Adam R, et al. Fatal acute HIV infection with aplastic anaemia, transmitted by liver graft [letter]. Lancet 1988; :1221-2.

13. Tindall B, Hing M, Edwards P, Barnes T. Mackie A, Cooper DA. Severe clinical manifestations of primary HIV infection. AIDS 1989:3:747-9.

14. Girard PM. Matheron S, Oksenhendler E. et al. Hépatite aiguë au cours des primoinfections par le virus HIV (human immunodeficiency virus). Gastroenterol Clin Biol 1987;11:803-4.

15. Barrier JH, Jouan M, Raffi F, et al. Acute infection with HIV-1 associated with spontaneous rupture of the spleen [abstract no 057]. In: Proceedings and abstracts of the 3rd European Conference on Clinical Aspects and Treatment of HIV Infection. Paris: Imprim, 1992.

16. Kieff ED, Johnson RP, Mark EJ. A 26-year-old woman with fever, diarrhea, leukopenia, thrombocytopenia, and hypoxemia. $\mathrm{N}$ Engl $\mathrm{J}$ Med 1989;321:454-63.

17. Del Rio C, Soffer O, Widell JL, Judd RL, Slade BA. Acute human immunodeficiency virus infection temporally associated with rhabdomyolysis, acute renal failure, and nephrosis. Clin Infect Dis $1990 ; 12: 282-5$.

18. Mahe A, Bruet A, Chabin E, Fendler JP. Acute rhabdomyolysis coincident with primary HIV-1 infection [letter]. Lancet 1989;2:1454-5.

19. Pedersen C, Nielsen JO, Dickmeis E, Jordal R. Early progression to AIDS following primary HIV infection [letter]. AIDS 1989;3:45-7.

20. Pedersen C, Lindhardt BO, Jensen BL, et al. Clinical course of primary HIV infection: consequences for subsequent course of infection. BMJ 1989;299: I 54-7.

21. Sinicco A. Sciandra M. Fora R. Caramello P. Gioannini P. Risk of developing AIDS after primary acute HIV-1 infection. [abstract no 03]. In: Proceedings and abstracts of the 3rd European Conference on Clinical Aspects and Treatment of HIV Infection. Paris: Imprim, 1992.

22. Tindall B, Cooper DA. Primary HIV infection: host responses and intervention strategies. AIDS 1991;5:1-14.

23. Tindall B, Gaines H. Imrie A, et al. Zidovudine in the management of primary HIV-1 infection. AIDS 1991;5:477-84.

24. Bulletin de l'Office fédéral de la santé publique [no 3.27.1]. Bern, Switzerland, 1992:15-24

25. Clark SJ, Saag MS, Decker WD, et al. High titers of cytopathic virus in plasma of patients with symptomatic primary HIV-I infection. $\mathrm{N}$ Engl J Med 1991;324:954-60. 
26. Anonymous Update: acquired immunodeficiency syndrome-United States, 1981-1990. JAMA 1991;265:3226-7.

27. Downs AM, Ancelle-Park RA, Brunet JB. Surveillance of AIDS in the European community: recent trends and predictions to 1991. AIDS 1990;4:1117-24.

28. Robert CF, Déglon JJ, Wintsch J, et al. Behavioural changes in intravenous drug users in Geneva: rise and fall of HIV infection, 19801989. AIDS 1990;4:657-60.

29. Biggar RJ, Johnson BK, Musoke SS, et al. Severe illness associated with appearance of antibody to human immunodeficiency virus in an African. BMJ 1986;293:1210-1.

30. Rabeneck L, Boyko WJ, McLean DM, McLeod WA, Wong KK. Unusual esophageal ulcers containing enveloped viruslike particles in homosexual men. Gastroenterology 1986;90: 1882-9.

31. Champion RH. Burton JL, Ebling FJG, eds. Rook/Wilkinson/Ebling: textbook of dermatology. 5th ed. Oxford: Blackwell Scientific, 1992:2728-9.

32. Champion RH, Burton JL. Ebling FJG. eds. Rook/Wilkinson/Ebling: textbook of dermatology. 5th ed. Oxford: Blackwell Scientific, 1992:2709-10.

33. Champion RH. Burton JL, Ebling FJG. eds. Rook/Wilkinson/Ebling: textbook of dermatology. 5th ed. Oxford: Blackwell Scientific. 1992:892-3, 940-2.

34. Champion RH, Burton JL, Ebling FJG, eds. Rook/Wilkinson/Ebling: textbook of dermatology. 5th ed. Oxford: Blackwell Scientific, 1992:893-4.

35. Hulsebosch HJ, Claessen FAP, van Ginkel CJW, Kuiters GRR, Goudsmit J. Lange JMA. Human immunodeficiency virus exanthem. J Am Acad Dermatol 1990:23:483-6.

36. Calabrese LH. Proffitt MR, Levin KH, Yen-Lieberman B, Starkey C. Acute infection with the human immunodeficiency virus (HIV) associated with acute brachial neuritis and exanthematous rash. Ann Intern Med 1987: 107:849-51.

37. Champion RH, Burton JL. Ebling FJG, eds. Rook/Wilkinson/Ebling: textbook of dermatology. 5th ed. Oxford: Blackwell Scientific, 1992:948-51.

38. Thin RT. Early syphilis in the adult. In: Holmes KK. Sexually transmitted diseases. New York: McGraw-Hill, 1990;221-30.

39. Calza AM, Kinloch S, Mainetti C. Salomon D, Saurat JH. Primary human immunodeficiency virus infection mimicking syphilis [letter]. J Infect Dis 1991;164:615-6.

40. Longworth DL. Spech TJ, Ahmad M, et al. Lymphocytic alveolitis in primary HIV infection. Cleve Clin J Med 1990;57:379-82.

41. Casalino E. Bouvet E, Bedos JP, Wolff M, Simon F, Vachon F. Acute HIV seroconversion and pneumonitis [letter]. AIDS 1991;5:1143-4.

42. Pedersen C. Gerstoft J, Lindhardt BO, Sindrup J. Candida esophagitis associated with acute human immunodeficiency virus infection [letter]. J Infect Dis 1987;156:529-30.
43. Podzamczer D. Casanova A. Santamaria P, Benasco C, Gudiol F. Esophageal candidiasis in the diagnosis of HIV-infected patients [letter]. JAMA 1988;259:1328-9.

44. Clotet B, Romeu J, Casals A, et al. Spontaneous resolution of Candida esophagitis in a seroconverting patient for HIV antibodies [letter]. Am J Gastroenterol 1988;83:1433.

45. Isaksson B, Albert J, Chiodi F, Furucrona A, Krook A, Putkonen P. AIDS two months after primary human immunodeficiency virus infection. J Infect Dis 1988;158:866-8.

46. Cilla G, Perez Trallero E, Furundarena JR, Cuadrado E, Iribarren JA, Neira F. Esophageal candidiasis and immunodeficiency associated with acute HIV infection [letter]. AIDS 1988;2:399-400.

47. Bonetti A, Weber R, Vogt MW, Wunderli W, Siegenthaler W, Luthy R. Co-infection with human immunodeficiency virus-type I (HIV1) and cytomegalovirus in two intravenous drug users. Ann Intern Med 1989;111:293-6.

48. Decker CF, Tiernan R, Paparello SF. Esophageal candidiasis associated with acute infection due to human immunodeficiency virus [letter]. Clin Infect Dis 1992;14:791.

49. Rabeneck L. Popovic M, Gartner S, et al. Acute HIV infection presenting with painful swallowing and esophageal ulcers. JAMA 1990;263:2318-22.

50. Carne CA, Tedder RS, Smith A, et al. Acute encephalopathy coincident with seroconversion for anti-HTLV-III. Lancet 1985;2:12068.

51. Hagberg L, Malmvall BE, Svennerholm L, Alestig K, Norkrans G. Guillain-Barré syndrome as an early manifestation of HIV central nervous system infection. Scand J Infect Dis 1986;18:591-2.

52. Piette AM, Tusseau F, Vignon D, et al. Acute neuropathy coincident with seroconversion for anti-LAV/HTLV-III [letter]. Lancet $1986 ; 1: 852$.

53. Elder G, Dalakas M, Pezeshkpour G, Sever J. Ataxic neuropathy due to ganglioneuronitis after probable acute human immunodeficiency virus infection [letter]. Lancet 1986;2:1275-6.

54. Denning DW, Anderson J, Rudge P, Smith H. Acute myelopathy associated with primary infection with human immunodeficiency virus. BMJ 1987;294:143-4.

55. Lima J, Ribera A, Garcia-Bragado F. Monteagudo M, Martin-Vega C, Bastida MT. Antiplatelet antibodies in primary infection by human immunodeficiency virus [letter]. Ann Intern Med 1987;106:333.

56. Von Sydow M, Gaines H, Sönnerborg A. Forsgren M, Pehrson PO, Strannegard $O$. Antigen detection in primary HIV infection. BMJ 1988;296:238-40.

57. Cooper DA. Tindall B. Wilson EJ, Imrie AA, Penny R. Characterization of $T$ lymphocyte responses during primary infection with human immunodeficiency virus. J Infect Dis 1988; 157:889-96.

58. Gaines H, von Sydow MAE, von Stedingk LV, et al. Immunological changes in primary HIV-1 infection. AIDS 1990;4:995-9. 